\title{
Os imigrantes poloneses em São Paulo pela lente do DEOPS
}

\author{
Erick Reis Goldiauskas Zen*
}

A comunidade de imigrantes poloneses estabelecida em São Paulo não formava um corpo homogêneo. Dentro desta conviveram diferenças de perspectiva política que não raramente entraram em conflito. Da mesma forma, as mudanças políticas no país de origem tiveram reflexo nas posturas políticas dos imigrantes. Todo esse complexo de relações, durante o processo de inserção, marcaram trajetórias e definiram padrões de comportamento políticosocial, bem como moldaram a memória desta comunidade. Uma das formas de percebermos essa dimensão foi analisando a documentação disponível no acervo do Departamento de Ordem Política e Social do Estado de São Paulo (DEOPS/SP), junto ao Arquivo do Estado. ${ }^{1}$

Enquanto órgão de Estado, o DEOPS foi moldado para ações de vigilância e repressão sistemática da sociedade e, para tanto, manteve os grupos de imigrantes sob constante suspeição. Os documentos produzidos revelam não só o olhar policial, mas a produção e circulação de vasto material impresso apreendido dos imigrantes e ativistas durante as investigações. A partir destas fontes diversas, ordenadas pela lógica policial, podemos encontrar uma série de referências que nos permitem alcançar as atividades políticas dos imigrantes e observar como estas foram vistas pelo Estado brasileiro.

Desde que se estabeleceram em São Paulo, os poloneses procuraram se

\footnotetext{
* Doutorando em História Social pela Faculdade de Filosofia Letras e Ciências Humanas da Universidade de São Paulo. Pesquisador do PROIN - Laboratório de Estudos da Memória Política Brasileira. Bolsista FAPESP.
} 
organizar com o objetivo de prestar assistência mútua bem como propiciar o ensino da língua e atividades culturais, estabelecendo laços de solidariedade. Importante ressaltar que as associações se formaram em prol da nacionalidade polonesa quando esta ainda se encontrava dividida entre três Impérios. Os fluxos imigratórios se realizaram principalmente diante das ofensivas russificadoras, levadas a cabo pela política czarista. Os poloneses imigraram para o Brasil como uma forma de preservarem a sua identidade, principalmente após os levantes da década de 1860 e da repressão que se seguiu ao levante de 1905. Assim, entre 1908 e 1936, de acordo com o Boletim do Serviço de Imigração e Colonização, ${ }^{2}$ ingressaram pelo Porto de Santos, como passageiros de 3 a classe, 15.220 poloneses.

A primeira associação polonesa se formou em 1892 com o nome de Sociedade Polonesa de Beneficência (Towarsutuno Polskie Dobroczynnosc). Em 1855 foi fundada a Federação Polaca de Socorro Fraterna (Towarzysdtwo Polskie Bratnia Pomolz Kaza Chorych) que contava com um fundo de auxílio para os enfermos, e que se fundiu com a Sociedade Polonesa União e Concórdia prevalecendo o nome da última. A Sociedade Polonesa União e Concórdia uniu-se à Sociedade Henrique Sienkiewucz, em 1922, passando a se chamar Sociedade Polonesa de São Paulo, após a independência da Polônia em 1918. Na década de 1930, a associação adotou o nome de Pilsudski, homenagem ao governante e "herói" da independência do país. A Sociedade destacou-se como a mais importante e atuante organização polonesa em São Paulo, identificada por seu caráter nacionalista de viés conservador, seguindo a orientação do governo daquele país entre 1918 e 1939 (FREITAS, 2001).

No pós-Segunda Guerra, o Brasil recebeu uma nova leva de imigrantes poloneses, denominados DIP (Displace Person). Durante a Guerra, muitos poloneses se dirigiram à Alemanha e ao se recusarem a retornar para seu país de origem - em virtude da instauração do regime comunista - foram reunidos nos Campos de Refugiados na Alemanha. Com o fim dos Campos, alguns países abriram a possibilidade de receber os DIPs, dentre os quais o Brasil. O país era vantajoso por não impor grande exigência para autorizar o ingresso, embora nos bastidores, o governo brasileiro fizesse uma seleção, "negociando" para que os diplomatas evitassem a entrada de judeus (CARNEIRO, 2001, p.115). De acordo com os dados do Departamento de Imigração e Colonização, ingressaram no estado de São Paulo, segundo matrícula na Hospedaria do Campo Limpo durante o triênio 1947-1949, 11.287 deslocados de guerra, dos quais 3.229 poloneses.

\section{O DEOPS vigia os poloneses}

Ao longo da década de 1930, observamos a participação de imigrantes poloneses em diversos movimentos políticos de esquerda, quer nas associações de classe, quer nas fábricas, participando de movimentos grevistas, o que pode ser verificado pelos processos de expulsão envolvendo poloneses durante o 
período Vargas (1930-1945), quando foram expulsos do Brasil 778 estrangeiros, dos quais $8,49 \%$ eram de nacionalidade polonesa, atrás apenas da portuguesa, 17\%; espanhola, $13,05 \%$ e japonesa, $10,84 \%$ (RIBEIRO, 2003).

No entanto, os poloneses não constituíram um movimento de esquerda que visasse abarcar todos os imigrantes dessa origem. Desta forma, não produziram periódicos em seu idioma com este viés ideológico ou formaram associações comunistas como, por exemplo, realizaram os italianos, espanhóis e os lituanos (ZEN, 2005 e 2010).

Essa situação foi modificada radicalmente com o fim da Segunda Guerra Mundial (1939-1945), quando a Polônia passou a integrar a esfera de influência soviética e o regime comunista foi ali instaurado. Durante a Guerra, um governo nacionalista se instaurou no exílio, em Londres, tendo inclusive participação nas operações do exército inglês. Depois da Guerra, os nacionalistas passaram a lutar pelo não reconhecimento do governo comunista. Este conflito, entre nacionalistas e comunistas, afetou os poloneses radicados no Brasil.

O Brasil reconhecia diplomaticamente a Polônia e, portanto, autorizou os diplomatas enviados pelo novo governo comunista. Foi em torno do consulado polonês em São Paulo que a colônia polonesa enfrentou os novos desafios. Por um lado, os nacionalistas não reconheceram a nova representação e sempre a denunciaram como produtora de propaganda comunista. Ao mesmo tempo, o consulado financiava publicações no Brasil, além de distribuir impressos poloneses. Atendendo à política daquele país, também passou a fazer campanha de repatriamento, sendo um dos responsáveis por emitir passaporte soviético. Diante desta movimentação, o DEOPS/SP colocou sob severa vigilância tanto o consulado como os poloneses aqui radicados, como o evidencia a quantidade de documentos de vigilância:

Às 9 horas, mais ou menos, parou em frente ao consulado um automóvel de chapa 25.764, do mesmo saindo um senhor de origem estrangeira. Foram entregues àquele consulado duas cartas, uma chegada da Polônia e outra da Hungria, informação obtida por intermédio do carteiro que é amigo de um dos Reservados. (...) Das 12 às 18 horas (...). Às 15 horas entrou no consulado em apreço um homem de origem estrangeira, que na saída carregava uma pasta de couro marrom e dois pacotes. 0 mesmo desceu do auto no 42626. Às 16:10 chegou outro cidadão, a pé, permaneceu no consulado cerca de 15 minutos. $^{3}$

O consulado polonês procurou cercar-se de comunistas capazes de realizar propaganda sobre as realizações do país. Para esse fim, viabilizou financeiramente a edição do periódico o Kurier Polskie (Mensageiro Polonês) que começou a ser impresso em 1948. Analisando as revistas apreendidas, podemos observar como essas procuravam veicular, através de fotografias e gráficos, a imagem da reconstrução da Polônia no pós-Guerra. Eram apresentados sorridentes operários, índices de crescimento em todas as áreas e monumentais edifícios 
públicos. O regime comunista era propulsor do progresso econômico e cultural. A revista procurava evitar o termo comunismo, como forma de driblar as autoridades brasileiras. Para tanto, usava eufemismos como "nova Polônia", "novo lar polonês".

O DEOPS designou o "SS" (integrante do Serviço Secreto) identificado como "ZM" para acompanhar a circulação do periódico e de seus colaboradores. Notamos que o mesmo era conhecedor do idioma polonês, pois além da tradução, classificava o teor dos artigos elaborando um perfil político dos seus autores. Em seu primeiro relatório de investigação, "ZM" explica que os artigos da Kurier Polskie eram "escritos com muito cuidado", mas que mesmo assim era possível identificar o "espírito anticlerical" e "anticapitalista". Por essa razão, considerava que sua produção não poderia ser realizada por membros da colônia polonesa, uma vez que esta era muito católica. ${ }^{4}$

Embora não especificado nos dossiês, suspeitava-se que o principal editor do Kurier Polskie fosse um funcionário do consulado polonês enviado ao Brasil com a finalidade de realizar propaganda comunista junto a esta comunidade. A impressão era inicialmente realizada na Tipografia Báltica, de propriedade do lituano Alexandre Bumblis, então editor do jornal lituano Zinios (Notícia). o Kurier Polskie não obteve o alcance esperado pelos seus editores. Sua publicação foi bastante irregular e, devido ao seu custo, a falta de leitores e de assinantes, encerrou suas atividades em 1950. Segundo versão policial, isto se deu por ordem do próprio consulado que não estaria mais disposto a arcar com seus custos.

Contudo, o Kurier Polskie não foi o único meio impresso para fazer circular a informação entre os poloneses comunistas. Os navios procedentes da Polônia que aportavam em Santos traziam diversas publicações que eram aqui difundidas. A polícia paulista demonstrou preocupação com essa movimentação. Suspeitava que os tripulantes pudessem fazer transporte de material subversivo, além de transmitir informações e instruções diretas da URSS para os ativistas comunistas em São Paulo. Essas suspeitas, em parte, se confirmaram quando o "SS" "ZM" passou a frequentar o porto de Santos, onde entrou em contato com a tripulação dos navios. Dessa forma, foi possível constatar que o transporte de diversos periódicos era realizado não só entre a Polônia e o Brasil. Através dos navios que ali aportavam, moldava-se uma rede de comunicação regular entre os ativistas poloneses radicados em diversos países do Cone Sul e a Polônia.

Entre os impressos obtidos por "ZM" constavam exemplares da revista Przekoroj, em cuja capa de dezembro de 1948, lê-se "Departamento Central do Comitê Polonês, Varsóvia". Neste exemplar, a polícia destacou os artigos de Jatolaw Iwaszkiewiscz, no qual foi mencionado o nome do pintor Candido Portinari. Na mesma revista, um artigo refere-se a um congresso de intelectuais realizado na cidade de Wroclaw, com destaque para uma fotografia de Jorge Amado, representante do Brasil.

O jornal Gloss Ludu (Voz do Povo), editado em Varsóvia, também figura 
entre os impressos obtidos. O de 14 de dezembro de 1948, por exemplo, apresenta do lado esquerdo da capa uma bandeira vermelha com o seguinte slogan "Congresso da Unificação da Classe Operária", seguido de fotografias dos líderes comunistas Marx, Engels, Lenin e Stalin. Na parte inferior, fotografias dos líderes comunistas poloneses Boleslaw Bierut e Josef Cyrankiewicz. Além de um conjunto de artigos sobre a importância da união dos partidos operários poloneses formando o Partido Comunista. $\mathrm{O}$ teor do jornal segue esta linha com artigos sobre a história do comunismo na Polônia, as perseguições durante o governo de Pilsudiski e a resistência durante a Segunda Guerra Mundial. Ao final desta parte, a reconstrução do país foi tratada em um artigo intitulado "Partido Comunista em cifras" que apresenta inúmeros gráficos sobre o desenvolvimento propiciado pelo partido. Na sequência, temos um artigo "Partido Operário Polonês" que elogia o Exército Vermelho pela libertação da Polônia, além de informar e comunicar sobre tratados comerciais da Polônia com a URSS. ${ }^{5}$

Ao investigar o navio polonês Warta, "ZM" encontrou exemplares da revista polonesa Kurier Polskie sobre a mesa do comandante do navio. Este material reforçava a suspeita de que se estaria realizando intercâmbio entre a imprensa comunista editada em São Paulo e os jornais poloneses. Acrescenta ZM que encontrou jornais comunistas e livros dentre os quais Nowe Drogi (Novos Caminhos) sobre a reconstrução da Polônia. ${ }^{6}$

Os jornais editados na Polônia costumavam publicar cartas de poloneses e de seus descendentes entusiasmados com o regime comunista. Um exemplo é a carta assinada por Bojanowski, residente no Paraná, publicada na Przekoroj. 0 autor se apresentou como um polonês que, há 55 anos estava no Brasil, tinha seis filhos e vinte e um netos, "todos sabendo ler e escrever em polonês". Além de cumprimentar as autoridades polonesas que estariam "trabalhando para o engrandecimento da Polônia Popular", agradecia o envio desta publicação ao Brasil que "nos orienta e une com o espírito da nova Polônia" com a qual teriam "sempre sonhado: uma Polônia para todos os poloneses". Adverte, no entanto, que a revista estaria sofrendo "injúrias" dos poloneses de Londres, que obedeciam fielmente as ordens hitleristas.

Entre os jornais editados em Buenos Aires, Argentina, foi apreendido o Polska Wyzwolava (Polônia Libertada) que traz a observação de que os fundos arrecadados com a venda seriam revertidos em prol da reconstrução da Polônia. Na edição de 16 de dezembro de 1948, anexado ao dossiê, o jornal traz uma série de notícias referentes ao Brasil. O artigo, "Presente dos poloneses do Brasil ao Presidente da República polonesa", relata como poloneses residentes no Paraná enviaram a Boleslaw Bierut, então presidente do país, uma lâmpada esculpida em pinheiro paranaense. No mesmo sentido, o pintor Cseslaun Lewandoski, residente em Curitiba, teria aproveitado a oportunidade para enviar duas aquarelas de sua autoria ao Museu Nacional de Varsóvia. Anunciava, ainda, que retratos do presidente polonês estariam sendo vendidos em diversos pontos do Brasil e que estes deveriam ornamentar as casas dos poloneses. 
Ainda sobre o Brasil, uma notícia chama a atenção: a proibição, na Polônia, da circulação do LUD (Povo), jornal editado pelos poloneses radicados no Paraná e um dos mais antigos em circulação. De marcado tom nacionalista, era desfavorável ao regime comunista. Realizava campanhas contra aquele regime e contra o consulado polonês em São Paulo. A sua proibição mostra como o regime comunista se preocupava com a produção impressa que questionasse a ordem estabelecida, mesmo por jornais produzidos por imigrantes. A ação de censura por si só é reveladora de que a publicação alcançava seu território em quantidade suficiente para ser incômodo ao regime. No sentido contrário, o fato de ter sido censurado pelo regime comunista o favoreceu diante das autoridades brasileiras, como expressa a Polícia Política de São Paulo. ${ }^{7}$

Se o campo comunista se articulava em torno do consulado e da realização das referidas publicações, as antigas associações polonesas que se manifestavam pelas páginas do $L U D$, trabalhavam no sentido contrário. Para estes, integrar a "comunidade" polonesa significava se posicionar como nacionalista, católico e, principalmente, anticomunista. A luta passava por se opor a cada ato e gesto realizado pelo consulado e por todos que se manifestassem pró-governo polonês, quer através de atividades festivas, comemorações públicas, ou de publicações.

As denúncias não poupavam nem mesmo membros do clero, como no caso do padre Paulo Sliuiski, acusado de ser colaborador comunista, pela rádio de Montevidéu e pela Sociedade Polonesa. Esta última passou as informações à polícia que, através de um relatório no ano de 1948, as levou ao delegado de Ordem Política e Social Gilberto de Andrade. De acordo com este, o padre seria responsável pela distribuição de literatura comunista entre poloneses e lituanos, além de se posicionar publicamente de forma favorável ao governo da Polônia, tanto assim que teria dirigido uma carta ao ministro polonês Wrzosek em visita ao Rio de Janeiro e a São Paulo. O relatório procurava demonstrar como o padre se valia de sua função de sacerdote para difundir ideias subversivas e como tal atitude era "perigosa". ${ }^{8}$ De acordo com o informante, em uma missa teria afirmado "O governo atual polonês é o melhor governo que tivemos durante toda a nossa história". ${ }^{9}$

Se as palavras proferidas pelo padre tinham este sentido ou tratava-se de uma invenção deliberada do informante para incriminá-lo, não nos é possível saber. No entanto, Sliuiski, em resposta às acusações sofridas, dirigiu cartas abertas para se "defender", principalmente das acusações realizadas pela rádio de Montevidéu. Nestas, sua posição para com o governo comunista polonês, fica bastante evidente, assim como, seu contato com as autoridades daquele país para atividades entre os poloneses. Na primeira carta, o padre argumenta contra a postura de parte dos poloneses de colocar todas as realizações do governo polonês como negativas. ${ }^{10}$

Os temas tratados nas cartas abertas são expressivos dos debates e da luta ideológica entre os favoráveis ao regime comunista e os nacionalistas. Entre os principais temas debatidos destaca-se o massacre de Katyn. O massacre 
da floresta Katyn foi realizado pelo Exército Vermelho durante a ocupação na Polônia, quando centenas de militares, oficiais do Exército polonês, que já haviam se entregado, foram sumariamente fuzilados. Este evento foi tomado pelos nacionalistas - e ainda o é - como o símbolo da dominação soviética e dos massacres cometidos contra os poloneses. Procuravam demonstrar, assim, que a ocupação e o governo decorrente eram ilegítimos, por se tratar de uma "violenta" imposição. Esse tema era de tal forma recorrente que o padre argumenta que "Sempre vocês repetem a mesma coisa. Aparece vosso "Katyn" já não sai pelas nossas gargantas".

O padre fez lembrar o massacre cometido pelos alemães na cidade de Oswiecein, onde teriam morrido "milhões". Compara, assim, o massacre de "milhares" ao de "milhões", como legitimador das ações soviéticas. Portanto, o debate acabava por se articular em torno dos massacres cometidos tanto pelo Exército nazista como pelo Exército Vermelho em legitimidade de suas práticas. Tal proposição pode nos causar estranheza, mas era - e podemos encontrar ainda hoje referências como estas nos discursos sobre a história da Polônia - uma forma de apreender os eventos de guerra e suas consequências. Os "malefícios" dos alemães são reforçados pelo padre Sliuiski, com a conclusão de que os poloneses não deveriam retomar os argumentos sobre Katyn "não imitais esses criminosos. Lembre-se nosso inimigo no 1 foram os alemães, no 2 os alemães, no. 3 os alemães". Na segunda carta aberta, Sliuiski reafirma as relações que mantinha com os representantes diplomáticos da Polônia no Brasil, na qual argumenta: Essas representações são legais e reconhecidas pelo governo brasileiro. Não me dedico aos trabalhos subterrâneos e ajo publicamente de acordo com as leis de Deus e dos Homens. ${ }^{11}$

A polícia adotou uma postura vigilante diante do posicionamento do padre Sliuiski e de suas relações com representantes diplomáticos da Polônia. Informes Reservados e Relatórios sobre o padre podem ser encontrados nos dossiês referentes aos poloneses. Nestes documentos de investigação foram anotadas as reuniões realizadas no consulado, projeções de filmes, festas. No entanto, Sliuiski não foi detido ou sofreu qualquer processo. ${ }^{12}$ Naquele momento eram outras as preocupações do DEOPS.

Preocupava as autoridades brasileiras a questão da repatriação dos poloneses - bem como dos lituanos e russos. No caso polonês, o centro difusor deste movimento era o consulado, como já colocamos. Seu trabalho não se limitou à solução de questões burocráticas para aqueles que desejavam retornar, o que seria sua função. Articulou uma verdadeira propaganda pelo repatriamento, através de órgãos de imprensa como o Kurier Polskie e de um jornal específico para essa finalidade editado em Varsóvia, o Repatrian. Somavam-se a estes, folhetos comemorativos que difundiam as conquistas econômicas e sociais da Polônia comunista e da União Soviética. A condição de vida dos trabalhadores e a prosperidade eram temas recorrentes que, certamente, produziram efeitos nos operários imigrantes aqui radicados. 
O trabalho do DEOPS, neste sentido, era o de impedir, ou pelo menos localizar as emissões de "passaportes soviéticos". Preocupado com a movimentação no consulado, a Polícia Política passou a vigiar sistematicamente aquele local, procurando identificar seus frequentadores e suas respectivas atividades, através de uma campana montada na frente do referido local. Pela expressiva quantidade de documentos sobre as atividades do consulado, bem como pelos jornais recolhidos, acreditamos que o DEOPS infiltrou algum investigador "Reservado" entre seus funcionários. Diariamente, eram enviados relatos das atividades do cônsul e dos demais funcionários: "Comunicamos a essa chefia, que, no consulado da Polônia existem nas gavetas dos funcionários carteiras do extinto $P C B$ e mais materiais de propaganda comunista". ${ }^{13}$

O mesmo informante relatou que "há dias" passaportes soviéticos chegaram ao consulado para serem entregues aos imigrantes radicados em São Paulo e que haviam solicitado cidadania. "Chegou há dias uma nova remessa de passaportes soviéticos no consulado polonês. Trata-se dos passaportes daqueles que há tempos pediram a cidadania soviética". ${ }^{14}$ Não dispomos de informações sobre a quantidade de repatriados. A polícia, embora vigilante, não registrou a detenção de nenhum indivíduo.

Através da documentação preservada pelo DEOPS, encontramos correspondências diplomáticas. Essas registraram uma delicada questão com relação aos filhos de poloneses nascidos no Brasil e que teriam retornado. Como na Polônia a naturalidade é determinada pela nacionalidade dos pais e no Brasil pelo local de nascimento, o governo brasileiro não tinha instrumentos legais para fazer retornar esses indivíduos, caso desejassem. Neste sentido, a Delegação brasileira em Varsóvia emitiu ofício ressaltando o problema, além de mostrar o drama vivenciado por aqueles que retornaram e não encontraram o tratamento e as condições que esperavam, tendo seus sonhos frustrados.

Passados os primeiros entusiasmos e encontradas as primeiras dificuldades vêem esses reimigrantes novamente juntar-se aos candidatos a visto que rondam os consulados estrangeiros (...) com os reimigrantes viajam seus filhos nascidos no Brasil, aos quais o governo Polonês não reconhece a nacionalidade, impedindo que assistamos praticamente a tais brasileiros.

Não possuímos outras informações sobre a situação dos imigrantes que voltaram bem como de seus filhos. Pesquisas com este tema ainda devem ser realizadas, consultando os arquivos da diplomacia polonesa e brasileira.

\section{Considerações finais}

Com os temas que aqui buscamos abordar, mostramos algumas facetas da imigração polonesa que ainda podem ser desenvolvidas. A partir da documentação produzida e acumulada pelo DEOPS, explicitamos uma série de relações e lutas políticas, bem como vínculos com poloneses radicados em outros países da 
América Latina, que muitas vezes não são considerados nas pesquisas existentes sobre estes imigrantes. Dessa forma, acreditamos contribuir para a formação de uma história política dos imigrantes que considere os conflitos ideológicos e políticos vivenciados por estes e destes com o Estado brasileiro, ressaltando como as mudanças no país de origem, bem como as redes de comunicação entre comunidades de mesma origem nacional moldam posturas políticas e sociais. Assim, a ideia de que os imigrantes formam uma base homogênea pode ser superada, bem como o discurso da própria comunidade que molda sua memória oficial apagando o que considera "inconveniente".

\section{Notas}

1 - O Presente artigo é o resultado parcial da pesquisa de mestrado Imigração e Revolução: Lituanos Russos e Poloneses sob vigilância do DEOPS (1924-1950), FFLCH/USP, 2006.

2 - Boletim do Serviço de Imigração e Colonização. № 2, São Paulo, outubro de 1940.

3 - Relatório de investigação de BR a Elpidio Reali, Delegado Especializado de Ordem Política, São Paulo, 18/10/1947. Fls., 19. Dossiê 30-E-3. DEOPS / SP, APESP.

4 - Informe reservado de ZM "SS", São Paulo, 26/05/1948, Dossiê 30-Z-85. DEOPS / SP, APESP.

5 - Relatório de Investigação de ZM ao delegado Gilberto da Silva Andrade, Chefe do "SS". Constam os exemplares anexados. São Paulo. 31/05/1949, fls., 9 e 10. Dossiê 30-E-3. DEOPS / SP, APESP.

6 - Relatório de ZM ao chefe do "SS" Gilberto Silva de Andrade. São Paulo, 28/09/1949. Dossiê 30-Z-85.3. DEOPS / SP, APESP.

7 - Jornal LUD anexado ao Dossiê 30-E-3. DEOPS / SP, APESP.

8 - Relatório dirigido ao delegado de Ordem Política Gilberto de Andrade. São Paulo, 12/07/1948. Fls., 3. Dossiê 30-G-7. DEOPS / SP, APESP.

9 - Idem.

10 - Carta aberta de Montevidéu "Honra Polonesa” do Padre Paulo Sliuiski, s /data. Fls., 7-8. Dossiê 30-G-7. DEOPS / SP, APESP

11 - Dossiê. 30-G-7. DEOPS / SP, APESP.

12 - Dossiês 30-Z-85.31 30-B-147.3, 50-Z-345-15. DEOPS / SP, APESP.

13 - Informe reservado do "SS", São Paulo, 10/03/1951. Fls., 103. Dossiê 30-E-3. DEOPS / SP, APESP.

14 - Idem.

\section{Referências}

CARNEIRO, Maria Luiza Tucci. Anti-Semitismo na Era Vargas. 3a edição, São Paulo: Perspectiva, 2001.

FREITAS, Sonia Maria. Falam os imigrantes: Armênios, chineses, espanhóis, italianos, de Monte San Giacomo e Sanza, lituanos, okinawanos, poloneses, russos, ucranianos, memória e diversidade cultural em São Paulo. Tese de Doutorado em História Social, FFLCH/USP, São Paulo, 2001.

RIBEIRO, Mariana Cardoso dos Santos. Venha o Decreto de Expulsão. A Legitimidade da Ordem Autoritária no Governo Vargas (1930-1945). São Paulo: Dissertação de Mestrado em História, FFLCH, USP, 2003. 
ZEN, Erick Reis Godliauskas. O Germe da Revolução. A Comunidade Lituana Sob Vigilância do DEOPS (1924-1950). São Paulo: Associação Editorial Humanitas, 2005.

ZEN, Erick Reis Godliauskas. Imigração e Revolução: Lituanos, Poloneses e Russos sob Vigilância do DEOPS. São Paulo: Edusp/Fapesp, 2010.

\title{
RESUMO
}

O propósito deste artigo é estudar as atividades políticas dos poloneses radicados no Estado de São Paulo, sob a vigilância da Polícia Política, entre os anos 1930 e 1950. Para tal, utilizamos os arquivos do Departamento de Ordem Política e Social (DEOPS/SP), sob a guarda do Arquivo do Estado. Procuramos compreender as lutas internas a esta comunidade, iniciadas a partir de diferenças políticas, principalmente entre comunistas e anti-comunistas. São analisadas a produção e a circulação de periódicos e de literatura política, impressos no Brasil, assim como em outros países da América e da Europa.

Palavras-chave: São Paulo (Brasil); imigrantes poloneses; Polícia Política.

\begin{abstract}
The main task of this article is to study political activities of Polish immigrants rooted in the state of São Paulo under the scrutiny of the Political Police between 1930 and 1950 . We will use as sources the files of the Departamento de Ordem Política e Social (DEOPS/SP), in charge of São Paulo State Archive. We try to understand the struggles inside these communities, born of antagonistic political views, specially between communists and anti-communists. The production and circulation of newspapers and political literature, printed in Brazil, as well as from other countries of the American continent or from Europe is analyzed.
\end{abstract}

Keywords: São Paulo (Brazil); polish immigrants; Political Police. 